\title{
Millennial storage of near-Moho magma
}

Euan J. F. Mutch ${ }^{1 *}$, John Maclennan ${ }^{1}$, Tim J. B. Holland ${ }^{1} \&$ Iris Buisman $^{1}$

${ }^{1}$ Department of Earth Sciences, University of Cambridge, Downing Street, Cambridge, CB2 3EQ, United Kingdom.

5 * To whom correspondence should be addressed; E-mail: ejfm2@cam.ac.uk, em0242@my.bristol.ac.uk

One Sentence Summary: Primary magmas that supply volcanoes are stored at the base of the crust for thousands of years.

\section{Abstract}

10 The lower crust plays a critical role in the processing of mantle melts and the triggering of volcanic eruptions by supply of magma from depth. Our understanding of the deeper parts of magmatic systems is obscured by overprinting of deep signals by shallow processes. We provide a direct estimate of magma residence time in basaltic systems of the deep crust by studying ultramafic nodules from the Borgarhraun eruption, Iceland. Modelling of $\mathrm{Cr}$-Al interdiffusion in spinel crystals provides a record of long-term magmatic storage on the order of one thousand years. This places firm constraints on the total crustal residence time of mantle derived magmas, and has important implications for modelling the growth and evolution of transcrustal magmatic systems.

\section{Main Text}

Understanding the temporal evolution of magmatic systems from micron to crustal scales has become a major focus in volcanology (1), driven by important advances in the use of crystal chemistry as a magmatic chronometer $(2,3)$. Compositional zonation in volcanic crystals has been integrated with diffusion models to show that the timescales of days to years preserved in the crystal record can be 
25 linked directly to volcanic monitoring data $(4,5,6,7)$. These short timescales are conceptually linked to magma mixing, remobilisation of crystal mush, and magma rise from storage regions prior to eruption. However, the timescales of magma storage and the behaviour of magma plumbing systems during periods of apparent quiescence are not well understood. Estimates of magma and mineral residence times in the crust have ranged from $10^{2}-10^{5}$ years (8). Parsing these timescales into different

30 crustal levels has proven difficult but is key to understanding trans-crustal magmatic systems. Storage timescales in shallow silicic systems can span the aforementioned range in near-solidus conditions of cold storage $(8,9)$ or in an eruptible high melt-fraction state $(10)$. In contrast, little is known about storage times in the mafic systems that dominate magmatism at mid-ocean ridges, ocean islands and in the deeper part of arc volcanoes. Direct storage times in the lower crust are notoriously difficult to

35 estimate by diffusion chronometry as shallow and mid-crustal processing obscure lower crustal signals through crystal equilibration and resorption. We estimate magma residence time in the lower crust by applying diffusion chronometry to observations of $\mathrm{Cr}$ number $(\mathrm{Cr} \#=\mathrm{Cr} /(\mathrm{Al}+\mathrm{Cr}))$ zoning in spinels contained in ultramafic nodules from the Borgarhraun eruption, Iceland. This eruption provides constraints on magmatic processes operating close to the crust-mantle boundary, called the 40 Moho.

Borgarhraun is an early postglacial (10.5-7 ka BP) primitive basalt flow from the Theistareykir System in the Northern Volcanic Zone of Iceland (11). Geothermobarometry and melt inclusion studies have shown that the magma crystallized near the Moho ( $24 \mathrm{~km}$ depth) from a

45 compositionally diverse set of primary mantle melts $(11,12,13)$. Fresh tephra from this eruption contains primitive crystals of olivine ( $\left.\mathrm{Fo}_{87-92}\right)$, clinopyroxene, $\mathrm{Cr}$-spinel and plagioclase $\left(\mathrm{An}_{80-90}\right)$. Mafic and ultramafic cumulate nodules are abundant with textural characteristics typical of storage and maturation in a crystal mush such as grain rounding and curved crystal edges (14). Wehrlitic nodules show olivine and Cr-spinel crystals enclosed in clinopyroxene (Fig. 1), a feature observed in 50 mafic plutonic rocks from layered intrusions (14), oceanic sections (15) and ophiolites (16). The clinopyroxene-hosted olivine and spinel crystals are associated with small melt pockets (Fig. 1) and 
are surrounded by thin layers of melt ( $\sim 2-10 \mu \mathrm{m}$ thick). We measured spinel widths of 20-600 $\mu \mathrm{m}$. Spinels with widths below $200 \mu \mathrm{m}$ have homogeneous Cr\# contents that vary between different nodules. Crystals larger than $200 \mu \mathrm{m}$ are compositionally zoned with rims similar in composition to

55 the small spinels and cores of higher Cr\#. Importantly, the Cr\# of these spinel cores scales with spinel size (Fig. 1). The eradication of compositional heterogeneity in the smaller spinels and the preservation of zonation in the larger spinels is likely to be controlled by a diffusive process. Smaller crystals completely equilibrated with their local environment, while larger crystals preserved higher Cr\# core compositions in a state of disequilibrium. We observed this effect in a large population of 60 spinels ( 100) across seven different nodules, which rules out the role of sectioning effects (Fig. S1S2).

We expect the crystallisation of the spinels and the surrounding clinopyroxene to take place within one year of magma emplacement (17). We used thermodynamic modelling to account for the spinel

$65 \mathrm{Cr} \#$ compositions by equilibration over a cooling interval of around $75^{\circ} \mathrm{C}$ (Fig. S3-S4), similar to the crystallisation interval of the Borgarhraun olivines $\left(1350-1215^{\circ} \mathrm{C}\right)(18)$. The spinels were initially encased in clinopyroxene at high temperature and subsequently equilibrated with the surrounding melt pockets and grain boundary films following cooling to lower temperature $\left(1215^{\circ} \mathrm{C}\right)$ (Fig. S5). We infer very little deformation of the spinels as they retained their equidimensional forms, which

70 precludes stress-directed lattice diffusion of $\mathrm{Cr}$ and $\mathrm{Al}$ to create the concentric zoning patterns that we observed (19).

We cannot resolve the geometry, extent, and the interconnectivity of the melt network from 2D sections of the nodules. However, previous studies have suggested melt pockets and interconnected 75 grain boundary liquid films play an important role in the final stages of crystallisation of large mafic intrusions $(20,14)$. The melt networks may also have been more extensive prior to clinopyroxene crystallisation, given the important role of the liquid in mush homogenisation (21). The composition 
(e.g. $\mathrm{Mg} \#$ and $\mathrm{Cr} \#$ ) of the melt pockets adjacent to the spinel crystals were different to that of the final carrier liquid (Fig. S6), which suggests that these melt networks were isolated from the open magma

80 body. The variability in spinel $\mathrm{Cr} \#$ between different nodules highlights heterogeneity within the mush and the development of micro-environments for spinel equilibration.

We used the FEniCS (22) finite element code to model 2D diffusion of $\mathrm{Cr}-\mathrm{Al}$ exchange in spinels, combined with a nested sampling Bayesian inversion (23) to constrain the timescales of mush storage

85 with robust estimates of uncertainty. We derived diffusivity equations for $\mathrm{Cr}$-Al exchange in $\mathrm{Cr}$-spinel that take into account the covariance between the underlying diffusive parameters $(24,25)$ (Fig. S7S8, Table S1). We ran the models using Gaussian prior distributions with $1 \sigma$ uncertainties for temperature $\left(1215 \pm 30^{\circ} \mathrm{C}\right)$, pressure $(0.8 \pm 0.14 \mathrm{GPa})(12,18)$, and ferric iron contents $\left(\mathrm{Fe}^{3+} / \mathrm{Fe}_{\text {total }}\right)$ of the system $(0.14 \pm 0.02)(26)$. We used a multivariate Gaussian prior distribution for the parameters of 90 the $\mathrm{Cr}-\mathrm{Al}$ interdiffusion coefficient as constrained by its covariance matrix (Table S2). We used the equilibration temperature of spinel rim compositions $\left(1215^{\circ} \mathrm{C}\right)$ that corresponded to a cooler crystal mush. We assumed the same initial core $\mathrm{Cr} \#$ of 0.41 for all crystals, based on the largest measurable spinel which was most likely to retain its original core composition (Fig. 2). This provided us with a maximum estimate of the storage timescale.

We applied our Bayesian inversion to 7 spinel crystals (Fig. S9-S19, Table S3) from 3 different nodules which converged to magma storage timescales with a median of 1400 years, and $95 \%$ of timescales being less than 4100 years (Fig. 3). These storage timescales we determined agreed with 3D spherical spinel diffusion models we conducted at $1215^{\circ} \mathrm{C}$ for different crystal radii to assess the timescales of diffusive equilibration for spinels of different sizes (Fig. 1). The Mg compositions of Borgarhraun plagioclase macrocryst cores have equilibrated with the mush conditions (Fig. S20-31). This means the coarsest of these crystals ( $1200 \mu \mathrm{m}$ radius) required approximately 570 years storage, assuming $3 \mathrm{D}$ diffusion in a spherical crystal at $1215^{\circ} \mathrm{C}$ and a core composition of $\mathrm{An}_{90}$ (Fig. S32). The 
timescale of $\mathrm{Mg}$ in plagioclase equilibration provides a minimum estimate of the storage time, consistent with our spinel models that require hundreds to thousands of years of storage.

${ }^{238} \mathrm{U}_{-}{ }^{230} \mathrm{Th}$ and ${ }^{226} \mathrm{Ra}-{ }^{230} \mathrm{Th}$ crystal residence ages from diverse tectonic settings range from $10^{2}-10^{5}$ years (Fig 4) (8). Discrepancies between these estimates and thermally-activated diffusion timescales show that magmatic crystals may have complex and protracted histories throughout the crust that are

110 largely independent of the melts that formed them and carried them to the surface for eruption (8). This highlights the difficulty in unpicking individual segments of magmatic evolution from bulk crystal ages integrated over zoned crystal populations. Overall crystal residence timescales in basaltic systems have previously been estimated as $10^{2}-10^{3}$ years by combining oxygen diffusion durations with U-series observations $(27,28)$, but these measurements do not provide a spatial context for the

115 depth of magma residence. In contrast, textural and petrological constraints from Borgarhraun unambiguously link the diffusion timescale with near-Moho storage. Olivine-hosted melt inclusions link the crystal cargo to the carrier liquid by concurrent mixing and crystallisation (11), meaning our results can be interpreted as magmatic storage times. Our diffusion chronometry approach therefore provides an opportunity for relative high temporal and spatial resolution of magmatic storage times in 120 mafic lower crustal systems (Fig 4).

Our storage time estimate for basaltic mushes in the lower crust have implications for understanding the timescale of magma transfer through the entire crustal column at a range of tectonic settings. Not only does this include mid-ocean ridges and ocean islands (e.g. Iceland and Hawaii), but also oceanic and continental arc settings where the lower crust is dominated by mafic and ultramafic magmatism as shown by exposed crustal sections (e.g. the Kohistan arc, Pakistan) (29), primitive erupted products $(5,30)$, and geophysical observations (31). There are no direct constraints on the magmatic storage times in the lower crust of arcs. We therefore propose that our results provide an initial guide to expected near-Moho storage times in other mafic systems. For ocean island settings, our results 
130 indicate that primary magma can be stored near the Moho for thousands of years following initial mixing and crystallisation (17). These magmas are rapidly transported over days to the mid or shallow crust (7), where there is further long-term storage and magma processing $(27,28)$. This impacts our understanding of mantle melt transport, which is based on ${ }^{226} \mathrm{Ra}$ excesses, and may lead to downwards revision of melting region porosities when millennial storage of magma in the crust is considered (32)

Crystal storage in shallow, silicic arc systems can take place over timescales of up to $10^{5}$ years, which is likely related to different thermal (1) and rheological properties when compared to basaltic systems. If the shorter processing times we have found apply to arc systems, then the upper crust may be episodically supplied with relatively young magma batches from the lower mafic crust (Fig. 4). The

140 shorter crystal and magma storage times in the lower crust might reconcile differences between melt production rates in the mantle and the frequency of large silicic eruptions (1). In each tectonic setting, punctuated magma storage and rapid transport is likely a prominent feature. While packets of magma fresh from the mantle melting region could take thousands of years to traverse the crust, storage could accommodate most of this time. This style of magma transfer will play a major role in the movement

145 of heat and volatiles through the crust and in controlling the connection between deep and surface geochemical reservoirs, such as the mantle and the atmosphere.

\section{References and Notes}

(1) K. V. Cashman, R. S. J. Sparks, J. D. Blundy, Science 355, eaag3055 (2017).

150 (2) F. Costa, R. Dohmen, S. Chakraborty, Reviews in Mineralogy and Geochemistry 69, 545 (2008).

(3) K. M. Cooper, Philosophical Transactions of the Royal Society A, 377, 20180009 (2019).

(4) K. Saunders, J. Blundy, R. Dohmen, K. Cashman, Science 336, 1023 (2012).

(5) P. Ruprecht, T. Plank, Nature 500, 68 (2013). 
(6) T. H. Druitt, F. Costa, E. Deloule, M. Dungan, B. Scaillet, Nature 482, 77 (2012).

155 (7) E. J. F. Mutch, J. Maclennan, O. Shorttle, M. Edmonds, J. F. Rudge, Nature Geoscience, (2019), doi: 10.1038/s41561-019-0376-9

(8) K. M. Cooper, A. J. Kent, Nature 506, 480 (2014).

(9) A. E. Rubin, et al., Science 356, 1154 (2017).

(10) M. Barboni, et al., Proceedings of the National Academy of Sciences 113, 13959 (2016).

160 (11) J. MacLennan, et al., Geochemistry, Geophysics, Geosystems 4 (2003).

(12) B. Winpenny, J. Maclennan, Journal of Petrology 52, 1791 (2011).

(13) D. A. Neave, K. D. Putirka, American Mineralogist 102, 777 (2017).

(14) M. B. Holness, et al., Journal of Petrology 48, 1243 (2007).

(15) K. M. Gillis, et al., Nature 505, 204 (2014).

165 (16) J. Korenaga, P. B. Kelemen, Journal of Geophysical Research: Solid Earth 102, 27729 (1997).

(17) J. MacLennan, Journal of Petrology 49, 1931 (2008).

(18) J. MacLennan, D. M'Kenzie, F. Hilton, K. Gronvöld, N. Shimizu, Journal of Geophysical Research: Solid Earth 108 (2003).

(19) K. Ozawa, Nature 338, 141 (1989).

170 (20) W. Meurer, M. Meurer, Contributions to Mineralogy and Petrology 151, 187 (2006).

(21) A. Thomson, J. Maclennan, Journal of Petrology 54, 745 (2012).

(22) M. Alnæs, et al., Archive of Numerical Software 3, 9 (2015).

(23) F. Feroz, M. Hobson, M. Bridges, Monthly Notices of the Royal Astronomical Society 398, 1601 (2009).

175 (24) A. Suzuki, A. Yasuda, K. Ozawa, Physics and Chemistry of Minerals 35, 433 (2008). 
(25) E. S. Posner, J. Ganguly, R. Hervig, Geochimica et Cosmochimica Acta 175, 20 (2016).

(26) O. Shorttle, et al., Earth and Planetary Science Letters 427, 272 (2015).

(27) I. N. Bindeman, O. Sigmarsson, J. Eiler, Earth and Planetary Science Letters 245, 245 (2006).

(28) K. M. Cooper, K. W. Sims, J. M. Eiler, N. Banerjee, Contributions to Mineralogy and Petrology 180 171, 54 (2016).

(29) O. Jagoutz, M. W. Schmidt, Chemical Geology 298, 79 (2012).

(30) C.C. Stamper, J. D. Blundy, R. J. Arculus, E. Melekhova, Journal of Petrology, 55, 1353 (2014).

(31) T. Parsons, et al., Geology, 26, 199 (1998).

(32) K. Sims, et al., Geochimica et Cosmochimica Acta 63, 4119 (1999).

\section{Acknowledgements}

We would like to thank Chris Richardson for helpful advice about FEniCS. Marie Edmonds and David Neave are also thanked for their comments on an early draft of this manuscript. Funding: This research was funded by a NERC studentship awarded to E.J.F.M (NE/L002507/1). Author

Contributions: The project was initially conceived by E.J.F.M and J.M. E.J.F.M. developed the

190 diffusion model. E.J.F.M. performed the EPMA and SEM analysis with help from I.B. I.B. conducted the QEMSCAN analysis and processing of QEMSCAN maps. T.J.B.H. conducted the thermodynamic modelling using THERMOCALC. E.J.F.M. did the diffusion modelling. E.J.F.M. and J.M. interpreted the results. E.J.F.M. wrote the first draft of the manuscript, which was revised by all authors.

Competing Interests: The authors declare that they have no competing financial interests. Data and

195 materials availability: All data collected and modelled as part of this study are included in the supplementary materials and supplementary data files. The diffusion model code and Bayesian inversion in their current form are available from https://github.com/EuanMutch/Spinel_DFENS. 
200 Supplementary Materials

Materials and Methods

Supplementary Text

Figs. S1 to S34

Tables S1 to S4

205

References (33-95)

\section{Figure Captions}

Fig. 1: Disequilibrium in cumulate nodules from beneath the Icelandic Moho. Al maps of Borgarhraun wehrlitic nodules with poikilitic texture (left) and accompanying plots that show spinel core $\mathrm{Cr} \#$ compositions with respect to their measured width (right). Al maps are coloured based on phase: yellow-grey corresponds to $\mathrm{Cr}$-spinel (Sp), reds to clinopyroxene (Cpx), black to olivine (O1), and grey to glass $(\mathrm{Gl})$. The grey curves are 3D spherical spinel diffusion models (modelled at 1215 ${ }^{\circ} \mathrm{C}$ ) conducted for different crystal radii and diffusion timescales (years). Error bars correspond to the standard deviation of multiple compositions sampled from each spinel core. (A, B) correspond to

215 sample BORG_NOD1_N3 and $(\mathbf{C}, \mathbf{D})$ to BORG_NOD3_N2.

Fig. 2: Timing diffusive equilibration of Borgarhraun spinel crystals. Left: 1D Cr\# profiles measured by electron microprobe (EPMA) across Borgarhraun spinels. Blue curves show the modelled 1D fit from the 2D finite element diffusion model (insets). Dashed lines are model initial conditions. The error bars are $1 \sigma$ standard deviations based on analytical uncertainties. Right: Temperature-time density plots for posterior distributions from the Bayesian inversion. The quoted time is the median with $1 \sigma$ uncertainties. $(\mathbf{A}, \mathbf{B})$ correspond to profile BORG_NOD1_N3_SP1_P1 and (C, D) to BORG_NOD3_N2_SP1_P1. 
225 Fig. 3: Storage time estimates of near-Moho magma. Cumulative frequency distributions showing the magma storage time estimates from the Bayesian inversion. Grey lines are distributions obtained by modelling individual spinel crystals. The black line is the cumulative frequency distribution of all of the modelled spinel crystals. The dashed blue line and the blue arrow are the minimum and the range of possible residence times based on $\mathrm{Mg}$ equilibration in plagioclase at $1215^{\circ} \mathrm{C}$. The light green region represents mush residence times based on bulk 3D spherical diffusion models shown in Fig. 1.

Fig. 4: Crystal residence times and storage depths for magmatic systems from different tectonic settings. Shaded boxes represent the range of storage depth (normalised to the Moho) and residence timescale estimates made for individual volcanoes or volcanic systems. Timescale estimates for all

235 eruptions except for Borgarhraun used U-series disequilibria, with residence times being calculated using the difference between crystallisation age and eruption age. The colour of the box edges corresponds to the average $\mathrm{SiO}_{2}$ content of whole rock sample used in the timescale estimates. The colour of the symbols corresponds to the tectonic setting. Data and references are in Table S4. 
Figures 

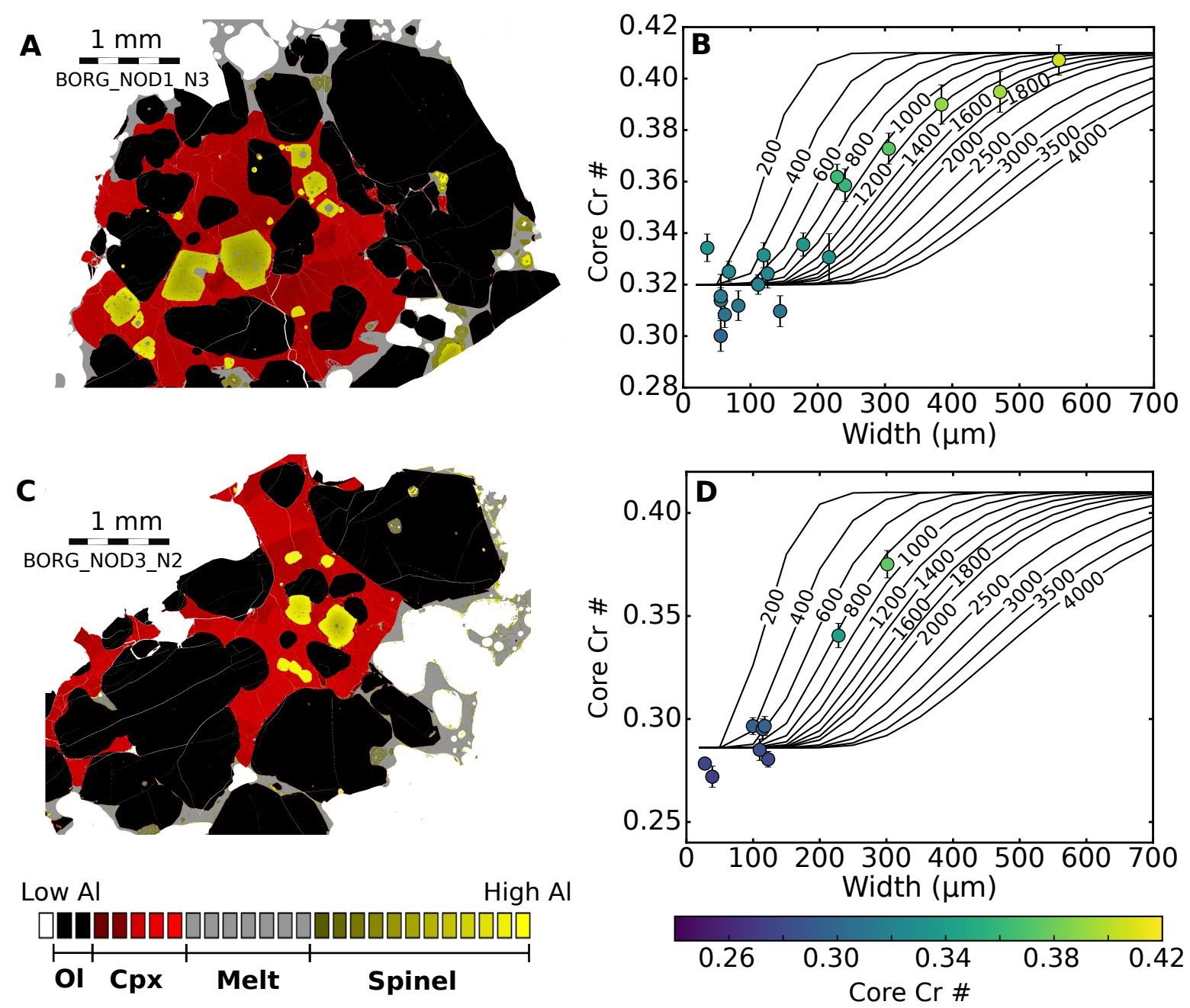

Fig. 1: Disequilibrium in cumulate nodules from beneath the Icelandic Moho. Al maps of Borgarhraun wehrlitic nodules with poikilitic texture (left) and accompanying plots that show spinel core $\mathrm{Cr} \#$ compositions with respect to their measured width (right). Al maps are coloured based on phase: yellow-grey corresponds to $\mathrm{Cr}$-spinel ( $\mathrm{Sp}$ ), reds to clinopyroxene (Cpx), black to olivine $(\mathrm{Ol})$, and grey to glass $(\mathrm{Gl})$. The grey curves are 3D spherical spinel diffusion models (modelled at $1215{ }^{\circ} \mathrm{C}$ ) conducted for different crystal radii and diffusion timescales (years). Error bars correspond to the standard deviation of multiple compositions sampled from each spinel core. (A, B) correspond to sample BORG_NOD1_N3 and $(\mathbf{C}, \mathbf{D})$ to BORG_NOD3_N2. 

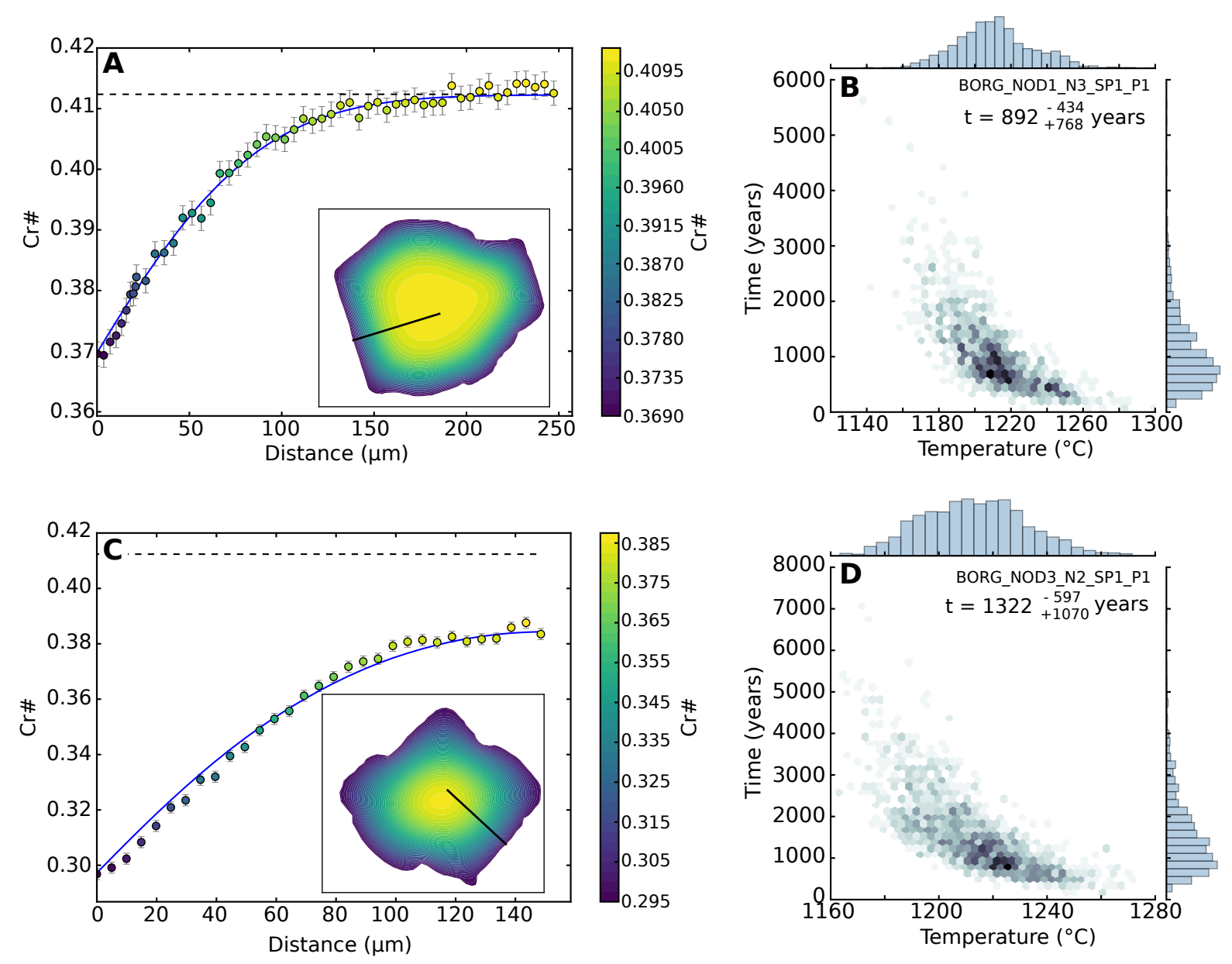

Fig. 2: Timing diffusive equilibration of Borgarhraun spinel crystals. Left: 1D Cr\# profiles measured by electron microprobe (EPMA) across Borgarhraun spinels. Blue curves show the modelled 1D fit from the 2D finite element diffusion model (insets). Dashed lines are model initial conditions. The error bars are $1 \sigma$ standard deviations based on analytical uncertainties. Right: Temperature-time density plots for posterior distributions from the Bayesian inversion. The quoted time is the median with $1 \sigma$ uncertainties. (A, B) correspond to profile BORG_NOD1_N3_SP1_P1 and $(\mathbf{C}, \mathbf{D})$ to BORG_NOD3_N2_SP1_P1. 


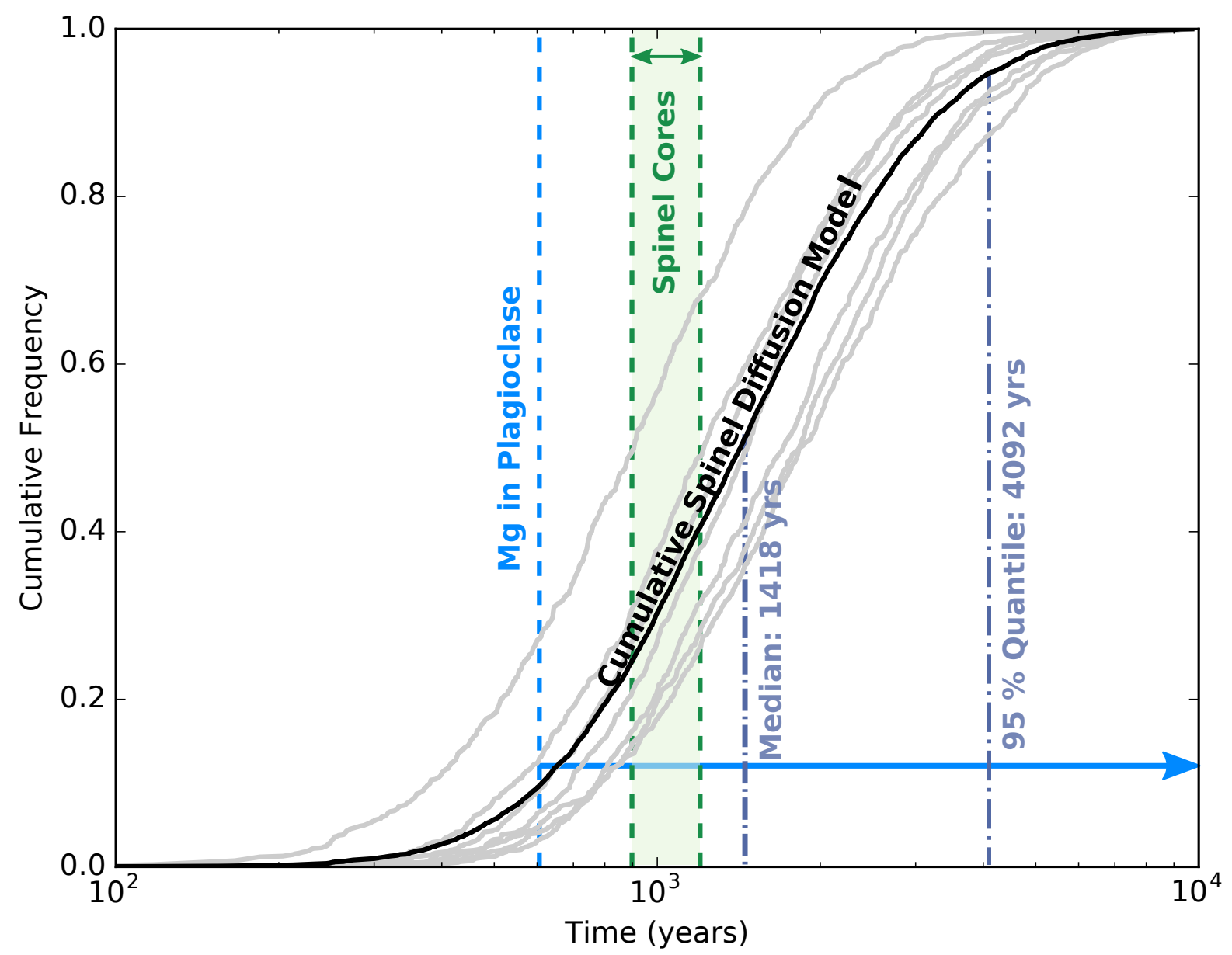

Fig. 3: Storage time estimates of near-Moho magma. Cumulative frequency distributions showing the magma storage time estimates from the Bayesian inversion. Grey lines are distributions obtained by modelling individual spinel crystals. The black line is the cumulative frequency distribution of all of the modelled spinel crystals. The dashed blue line and the blue arrow are the minimum and the range of possible residence times based on $\mathrm{Mg}$ equilibration in plagioclase at $1215^{\circ} \mathrm{C}$. The light green region represents mush residence times based on bulk 3D spherical diffusion models shown in Fig. 1. 


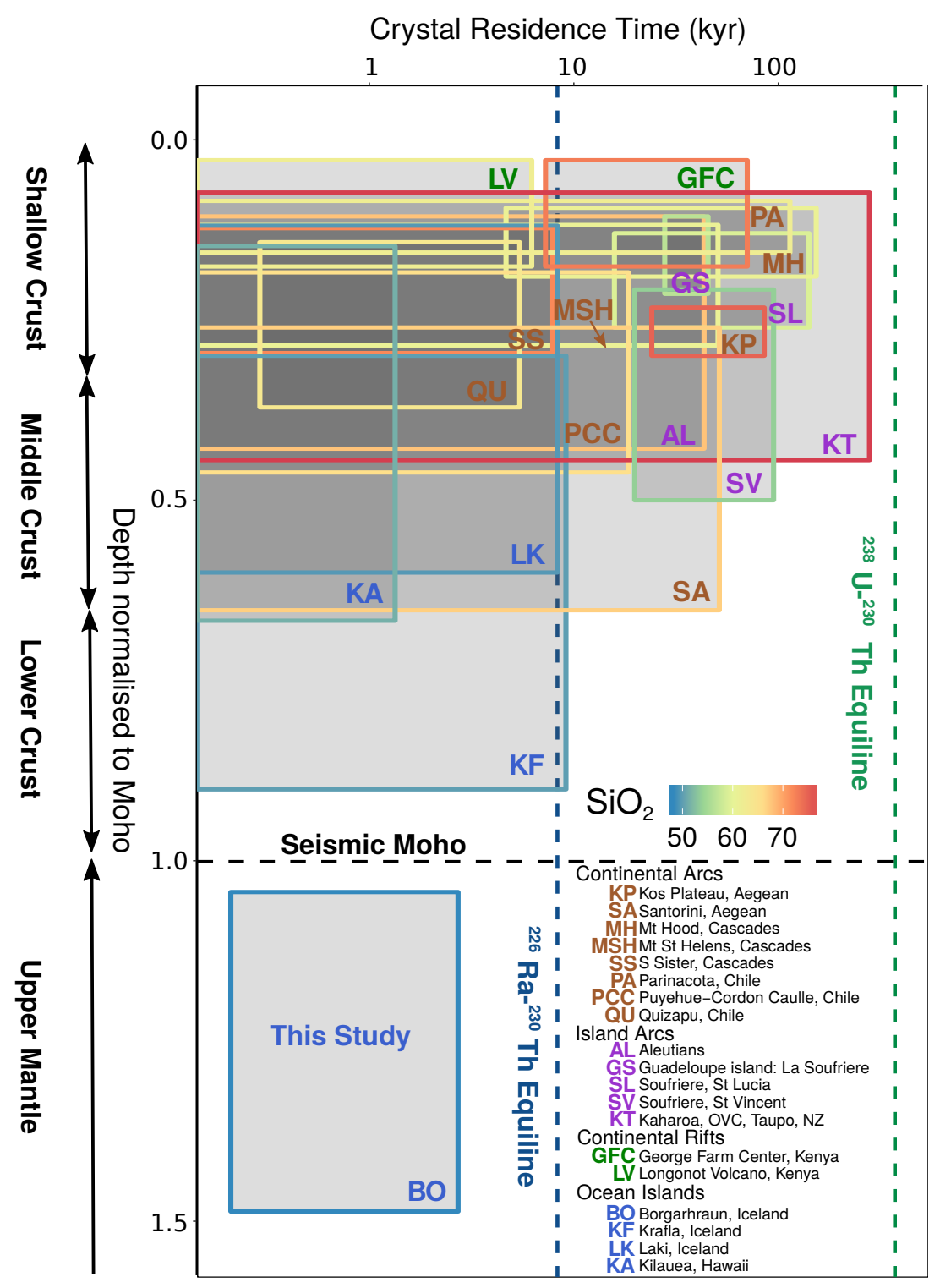

Fig. 4: Crystal residence times and storage depths for magmatic systems from different tec-

tonic settings. Shaded boxes represent the range of storage depth (normalised to the Moho) and residence timescale estimates made for individual volcanoes or volcanic systems. Timescale estimates for all eruptions except for Borgarhraun used U-series disequilibria, with residence times being calculated using the difference between crystallisation age and eruption age. The colour of the box edges corresponds to the average $\mathrm{SiO}_{2}$ content of whole rock sample used in the timescale estimates. The colour of the symbols correspongs to the tectonic setting. Data and references are in Table S4. 